\title{
PERCEPÇÃO DA EQUIPE MULTIDISCIPLINAR ACERCA DA ASSISTÊNCIA HUMANIZADA NO CENTRO CIRÚRGICO
}

\author{
Perception of the multidisciplinary team concerning humanized assistance at the surgical center
}

Percepción del equipo multidisciplinar sobre la asistencia humanizada en el centro quirúrgico

Beatriz Coêlho Barboza ${ }^{1 *}$ (D), Carlos Alberto Lopes da Silva Costa Sousa ${ }^{2}$ (D), Lorena Araruna de Souza Morais ${ }^{3}$ (D)

RESUMO: Objetivo: Compreender as percepções dos profissionais da equipe multidisciplinar acerca da humanização no centro cirúrgico. Método: Estudo de abordagem qualitativa, com fins descritivos, cuja coleta de dados ocorreu em um hospital público regional de média complexidade, de Brasília, Distrito Federal, no período de agosto a outubro de 2019, com 18 profissionais das áreas médica e de enfermagem. Realizou-se entrevista aberta e de caráter individual composta de cinco perguntas norteadoras, examinadas por meio da análise de conteúdo de Bardin. Resultados: As respostas a cada uma das questões foram categorizadas, considerando-se que a assistência humanizada foi percebida como a busca pelo bem-estar dos pacientes, mantendo relação de empatia pelo próximo com enfoque no atendimento holístico. Conclusão: A humanização envolve aspectos inerentes à condição de ser humano, e, para sua efetivação, é necessário o envolvimento de toda a equipe multidisciplinar nos cuidados com os pacientes.

Palavras-chave: Humanização da assistência. Centros cirúrgicos. Assistência à saúde. Equipe de assistência ao paciente. Comunicação interdisciplinar.

ABSTRACT: Objective: To understand the perceptions of professionals of the multidisciplinary team concerning humanization in the surgical center. Method: This is a qualitative study, with descriptive purposes, whose data collection took place in a regional public hospital of medium complexity, in Brasília, Federal District, from August to October 2019, with 18 professionals in the medical and nursing areas. An open and individual interview was conducted, composed of five guiding questions, analyzed through Bardin's content analysis. Results: The answers to each of the questions were categorized, considering that humanized assistance was perceived as the search for the patients' well-being, maintaining a relationship of empathy for others, and focusing on holistic care. Conclusion: Humanization involves aspects inherent in the condition of being human and, for its effectiveness, the involvement of the entire multidisciplinary team in patient care is necessary.

Keywords: Humanization of assistance. Surgicenters. Delivery of health care. Patient care team. Interdisciplinary communication.

RESUMEN: Objetivo: Comprender las percepciones de los profesionales del equipo multidisciplinar sobre la humanización en el quirófano. Método: Estudio de abordaje cualitativo, con fines descriptivos, cuya recolección de datos se realizó en un hospital público regional de mediana complejidad, en Brasilia, Distrito Federal, de agosto a octubre de 2019, con 18 profesionales de las áreas médica y de enfermería. Se implementó una entrevista abierta e individual, compuesta por cinco preguntas orientadoras, analizadas a través del análisis de contenido de Bardin. Resultados: Se categorizaron las respuestas a cada una de las preguntas, considerando que el cuidado humanizado se percibía como la búsqueda del bienestar de los pacientes, manteniendo una relación de empatía por los demás con un enfoque de cuidado integral. Conclusión: Se pudo entender que la humanización involucra aspectos inherentes a la condición del ser humano y que, para su efectividad, es necesario involucrar a todo el equipo multidisciplinario en el cuidado de los pacientes. Palabras clave: Humanización de la atención. Centros quirúrgicos. Prestación de atención de salud. Grupo de atención al paciente. Comunicación interdisciplinaria.

\footnotetext{
'Mestre em Saúde Coletiva pela Universidade de Brasília. Professora assistente no Instituto Superior de Educação de Brasília - Brasília (DF), Brasil. ${ }^{2}$ Enfermeiro pelo Centro Universitário Instituto de Educação Superior de Brasília. Enfermeiro assistencial do Hospital Anchieta - Brasília (DF), Brasil. ${ }^{3}$ Pós-graduanda em Docência em Enfermagem pela Faculdade Unyleya - Brasília (DF), Brasil.

*Autora correspondente: beatrizcoelhob@gmail.com

Recebido: 12/02/2020 - Aprovado: 26/10/2020

https://doi.org/10.5327/Z1414-4425202000040004
} 


\section{INTRODUÇÃO}

A humanização representa as condutas que visam prescindir os instintos e agir de acordo com a racionalidade e, desse modo, estar em conformidade com valores morais e com a benevolência para com o próximo. Para consolidar essas medidas no âmbito da qualificação dos serviços de saúde, instituiu-se, em 2003, a Política Nacional de Humanização (PNH), que estipula estratégias que integram a boa gestão e a assistência, com o intuito de efetivar, na prática assistencial, os princípios do Sistema Único de Saúde (SUS) que promovem a humanização ${ }^{1,2}$.

A humanização da assistência possui diferentes formatos de interpretação, pela sua configuração subjetiva e individual. No ponto de vista jurídico, pode ser percebida como um direito inerente a qualquer pessoa. Os avanços tecnológicos são de grande importância para a prestação de cuidados aos pacientes assistidos no centro cirúrgico (CC), porém é possível evidenciá-los como complicadores ao processo de humanização. Tais circunstâncias são decorrentes da crescente mecanização assistencial, o que torna imprescindível a necessidade de humanizar as relações entre profissionais e pacientes, porém a conjuntura abordada não é auspiciosa à sua efetivação ${ }^{3,4}$.

O CC corresponde ao espaço hospitalar destinado à realização de procedimentos anestésico-cirúrgicos e à recuperação pós-anestésica. A área representa um ambiente de cuidados intensificados e que exige assistência da equipe multidisciplinar voltada às necessidades específicas de cada paciente. Por esse motivo, as atividades desse local devem ser incumbidas de uma assistência sistematizada e minuciosa, baseada nas normas institucionais, a fim de condicionar a segurança e o bem-estar dos pacientes e dos profissionais de saúde 5,6 .

As atribuições voltadas à assistência no CC necessitam de empenho maior dos profissionais que lá trabalham, fato esse relacionado à vulnerabilidade do paciente que já se apresenta lânguido, o que exige da equipe uma assistência humanizada baseada na comunicação e na receptividade. Porém essa situação se torna complexa quando se observa que, ante esse cenário, a equipe se sente sobrecarregada pela grande demanda de trabalho em suas atividades, o que gera maior tensão e responsabilização $0^{7,8}$.

O trabalho em equipe nos serviços de saúde deve proporcionar aos seus pacientes melhor qualidade de atendimento, visando à sua recuperação e à reinserção o mais breve possível em seu meio familiar e social. Essas trocas de experiências multiprofissionais, aliadas à comunicação efetiva e à humanização na assistência, ainda que com muitos desafios a serem enfrentados, asseguram ao paciente um tratamento eficaz e de qualidade, permitindo a reabilitação de sua saúde ${ }^{9}$.

É de suma importância aprimorar os conhecimentos da equipe cirúrgica sobre o tema humanização. Um enfoque maior desse assunto nas graduações e nas instituições que prestam serviços de assistência à saúde é de grande relevância. Palestras, reuniões e congressos, aliados a um maior comprometimento de acadêmicos, professores e profissionais de saúde sobre o processo de humanização, aprimorariam a qualidade dos atendimentos prestados aos pacientes, facilitando, assim, o entendimento sobre suas singularidades, anseios e sentimentos, ou seja, percebendo o paciente como um ser "bio-psico-sócio-espiritual" que necessita de atenção, cuidados e afeto $^{10,11}$.

Ante o exposto, surge o interesse em entender qual é a percepção da equipe multidisciplinar do CC acerca da aplicação da assistência humanizada. Esta pesquisa poderá acarretar melhor compreensão e reflexão a respeito dos processos de humanização na prestação dos cuidados aos pacientes cirúrgicos por parte dos profissionais pertencentes à equipe do setor, além do mais, pode agregar pesquisas futuras como base de dados.

\section{OBJETIVO}

Compreender as percepções dos profissionais da equipe multidisciplinar, mediante seus conhecimentos e suas experiências de ordem prática, referentes à aplicabilidade da humanização no ambiente de CC.

\section{MÉTODO}

Trata-se de estudo de abordagem qualitativa, com fins descritivos. A coleta de dados ocorreu no CC de um hospital público regional de média complexidade, compreendido na região de saúde oeste, Ceilândia, de Brasília, Distrito Federal, no período de agosto a outubro de 2019.

A coleta de dados ocorreu por meio de uma entrevista de caráter individual, composta de cinco perguntas norteadoras abertas:

- o que é humanização para você?; 
- para você, quais são as estratégias que podem ser utilizadas para humanizar o atendimento no CC?;

- para você, qual é a principal dificuldade para humanizar a assistência no CC?;

- como sua profissão pode contribuir para humanizar a assistência no CC?;

- em sua concepção, como deve ocorrer a responsabilização da assistência humanizada da equipe multiprofissional?

Foram entrevistados 18 profissionais, sendo eles: 5 enfermeiros, 5 técnicos de enfermagem, 5 cirurgiões e 3 anestesiologistas. Na categoria dos anestesiologistas, almejava-se cinco profissionais, porém, pela indisponibilidade de alguns no momento da entrevista, apenas três participaram da pesquisa.

Critérios de inclusão: profissionais pertencentes à equipe multidisciplinar do CC e que estavam presentes no momento da entrevista.

Critérios de exclusão: profissionais pertencentes à equipe multidisciplinar do CC que se recusaram a participar da pesquisa ou que estavam trabalhando no horário da entrevista.

O tratamento dos dados ocorreu por meio da análise de conteúdo proposta por Bardin. De acordo com a autora, esse método compõe um conjunto de técnicas que analisa a comunicação dos sujeitos com base em processos objetivos e sistemáticos de descrição dos conteúdos das mensagens. Dessa forma, proporciona uma observação acurada sobre as mensagens e o entendimento dos comportamentos dos entrevistados, oportunizando melhor compreensão sobre suas percepções ${ }^{12,13}$.

As entrevistas foram gravadas e transcritas, seguidas de extenuante leitura do material, destacando as principais palavras e ideias-chave, categoricamente analisadas e estruturadas.

As falas foram protegidas pelo uso de siglas e números que indicam a categoria do profissional entrevistado, objetivando preservar seu anonimato. Para a categoria de enfermeiros, empregou-se a sigla "ENF", para os técnicos de enfermagem, a sigla "TEC ENF", cirurgiões, "CIRG”, e anestesiologistas, "ANEST", sendo elas sucedidas de numeração relativa à ordem de realização das entrevistas.

A pesquisa está em conformidade com os critérios ético-legais estabelecidos pela Resolução no 466 de 2012, do Conselho Nacional de Saúde. O projeto foi aprovado pelo Comitê de Ética e Pesquisa do Instituto de Educação Superior de Brasília (CEP/IESB), sob CAAE nº 15040119.7.0000.8927, e pelo Comitê de Ética e Pesquisa da Fundação de Ensino e Pesquisa em Ciências da Saúde (CEP/FEPECS), sob o CAAE n ${ }^{\circ}$ 15040119.7.3001.5553.

A formalização da aceitação em participar da pesquisa ocorreu pela assinatura do Termo de Consentimento Livre e Esclarecido, dispondo sobre informações pertinentes à pesquisa, e pela assinatura do Termo de Autorização para Utilização de Imagem e Som de Voz para Fins de Pesquisa.

\section{RESULTADOS}

Os 18 entrevistados que compuseram a amostra deste estudo consideraram vários pontos e percepções acerca da assistência humanizada no CC, conforme se demonstra na categorização dos cinco questionamentos abordados nesta pesquisa.

\section{Questão 1: Percepção da equipe multidisciplinar acerca do conceito de humanização}

\section{Categorias: Bem-estar. Empatia. Atendimento holístico.}

Quando questionados sobre o que seria humanizar, os entrevistados mencionaram que é oferecer bem-estar aos pacientes, buscando atendê-los de maneira digna, fazendo com que se sintam acolhidos e respeitados, a fim de ofertar um atendimento de qualidade: "Humanização é fazer com que o paciente se sinta bem, tratando-o o mais humanamente possível. $\mathrm{O}$ paciente vai se sentir melhor, mais seguro" (TEC ENF 01); "Para mim, é tratar bem o paciente, procurar saber o que ele está sentindo" (TEC ENF 05); "Humanização é humanizar o paciente [...], dando a melhor qualidade para ele" (ENF 04).

Os entrevistados destacaram, também, a importância de manter relação de empatia pelo próximo, espelhando-se nas angústias do outro e procurando sanar dúvidas acerca do que será realizado: "Para você ser humanizado, você tem que se colocar no lugar do outro" (TEC ENF 02); "Humanização é tratar o paciente como um membro da minha própria família" (CIRG 02); "É você se colocar no lugar do outro e que você faz o melhor explicando para o outro tudo, todos os procedimentos que vão ser realizados, da melhor maneira possível” (ENF 02).

Evidenciaram, ainda, como de grande relevância prestar um atendimento com enfoque holístico, abrangendo a integralidade dos pacientes atendidos no CC: "Humanização é tratar o paciente de forma íntegra, não só pela doença dele" (CIRG 03); "É ter essa visão do paciente como um todo, não somente ver o paciente com a doença que precisa ser operada” (ENF 01); "É quando a gente atende ao paciente, 
visando não somente sanar aquele problema de saúde, mas olhá-lo como um todo" (ENF 03); "Humanização dentro do centro cirúrgico é o entendimento do paciente como um todo, inclusive seus receios" (ANEST 03).

\section{Questão 2. Estratégias que podem ser usadas para humanizar a assistência no CC}

\section{Categorias: Trabalho em equipe. Comunicação efetiva.}

Quanto a esse questionamento, os entrevistados destacaram como estratégias a necessidade do trabalho em equipe, em que todos são importantes para o cumprimento dos processos de humanização: "As estratégias vêm desde a administração até chegar ao pessoal da limpeza. Estratégias em relação à conduta com o paciente" (TEC ENF 03); "Acho que se é equipe multidisciplinar se ela trabalhasse mais em conjunto" (ENF 03).

Apontaram, também, que a comunicação efetiva favorece a prestação de cuidados humanizados: "Comunicação entre as equipes [...] acho que é isso basicamente. Estabelecer uma boa relação entre as equipes" (ANEST 02);

Integração da equipe, pois muitas vezes a gente tem informações isoladas [...]. O cirurgião passa uma informação ao paciente que é diferente do anestesista, da enfermagem, justamente porque a gente não conversou antes, a gente não discutiu o caso. Então, uma estratégia seria a discussão prévia sobre cada caso individualmente. Acho que essas seriam estratégias interessantes para tornar $\mathrm{o}$ atendimento mais humanizado para o paciente (ANEST 03).

\section{Questão 3. Principais dificuldades para humanizar a assistência no CC}

$$
\begin{aligned}
& \text { Categorias: Excesso de pacientes. } \\
& \text { Poucos funcionários. Muitas atribuições. }
\end{aligned}
$$

Os participantes deste estudo apontaram o excesso de pacientes, poucos funcionários e muitas atribuições como impasses para a prestação de cuidados humanizados: "Essa é a maior dificuldade porque ele fica pouco tempo e a assistência é curta. [...] Falta de tempo [...] e temos poucos enfermeiros. É um enfermeiro por plantão [...]. É muito trabalho para uma pessoa só, e isso também dificulta muito" (ENF 01); "Acredito que seja o volume, né? [...] muitos pacientes [...], pouco tempo e o número pequeno de funcionários para você poder dar essa atenção necessária que cada paciente merece" (ANEST 01); "Número muito grande de pacientes [...]. Quando há muitos pacientes, a gente fica com muito trabalho" (TEC ENF 01).

\section{Questão 4. Contribuição profissional para humanizar a assistência no CC}

Categorias: Promover orientação. Oferecer conforto.

Ao serem indagados sobre a contribuição de sua profissão para a humanização da assistência, os entrevistados citaram a promoção de orientação e conforto aos pacientes e aos seus acompanhantes: "Quando o paciente tiver qualquer dúvida em relação ao procedimento, porque o paciente vem para cá e não sabe que cirurgia vai fazer, o que que vai fazer $[\ldots]$ conversar com paciente e transmitir segurança. Eu acho que é você dar atenção" (TEC ENF 04); "Conversar com o paciente, né? [...] Ver quais são suas ansiedades, quais são suas angústias. Eu acho que a nossa função é principalmente essa" (CIRG 01);

Acolher melhor o paciente, confortar, não só acalmar também, né? Porque ele vai chegar com medo do ambiente que ele não conhece bem, já está com medo pelo procedimento cirúrgico, tudo. Orientar da melhor forma possível o que vai ser realizado (CIRG 02).

\section{Questão 5. Responsabilização da assistência humanizada para a equipe multiprofissional}

Categorias: Tarefa individual. Tarefa coletiva. Tarefa das chefias.

Relativo a essa abordagem, os entrevistados trouxeram respostas prolixas: alguns referiram ser uma tarefa coletiva, outros, individual, e ainda houve a menção de que são necessárias cobranças à equipe por parte das chefias para a implementação das práticas humanizadas: "Cada um ocupando seu papel já consegue fazer essa responsabilização” (TEC ENF 02);

$\mathrm{Eu}$ acho que tem que ser uma responsabilização conjunta. Acho que todo mundo é profissional de saúde, todo mundo quer um bem; em minha opinião, um bem único, não um bem próprio, certo? Todo mundo quer que o paciente saia daqui da melhor forma possível (CIRG 03);

"Eu acho que a chefia, a chefia de equipe, tanto a chefia de enfermagem como a médica, deveria deixar um protocolo de atendimento" (ENF 03); "A responsabilização tem que ser delegada pelos chefes das equipes e dos serviços de maneira geral, delegada e instituída pelas instâncias superiores do serviço" (ANEST 02). 


\section{DISCUSSÃO}

A humanização tem grande influência no processo saúde-doença e vai muito além da tecnicidade assistencial prestada ao paciente. Humanizar significa ter amor pelo que se faz, baseando-se nos princípios éticos e morais, dando prioridade à vida humana, buscando sempre o bem-estar dos que precisam de atenção e cuidados ${ }^{7}$. Em conformidade ao exposto, os entrevistados desta pesquisa elencaram alguns pontos, como o bem-estar do paciente e a empatia pelo próximo, além de prestar atendimento com enfoque holístico, descrevendo as características que envolvem o complexo ato de prestar cuidados humanísticos.

É nítido que há consenso entre as falas dos integrantes da equipe multidisciplinar do CC, participantes desta pesquisa, de que prestar um atendimento humano, entre outras percepções, significa proporcionar conforto ao paciente. Concernente a isso, um estudo aponta que a relação humanística entre o profissional e o paciente cirúrgico é de vital relevância para uma boa experiência perioperatória ${ }^{7}$. Outra pesquisa descreve como fundamental o diálogo e a interação entre profissional e paciente, tornando viável a horizontalização das interações humanas, propiciando dignidade ao sujeito e compreensão dos seus sentimentos ${ }^{14}$.

Além do mais, conciliando o que foi aludido anteriormente sobre a prestação do atendimento holístico, que abrange a integralidade dos fundamentos físicos, psíquicos, sociais e espirituais do paciente, é possível garantir qualidade na aplicação prática do seu direito à saúde. Corroborando essa visão, um estudo contextualiza a importância da globalização da assistência à saúde, proporcionando atendimento que atenda a todas as demandas do paciente, e que uma separação desses elementos pode interferir de forma negativa na estruturação de uma relação terapêutica efi$\mathrm{caz}^{15}$. Portanto, ao tratar os pacientes com eficiência e afeto, dando-lhes atenção, visando ao bem-estar, é possível ganhar a sua confiança e facilitar a prestação de cuidados, pois o paciente se sente acolhido e seguro perante a equipe que o cerca. Essa assistência humanizada vai além de apenas estar fisicamente próximo ao paciente. Para que ela aconteça, é necessário, também, ser empático, buscando maior reflexão acerca dos anseios e das necessidades do próximo, autorrefletindo-se na sua dor e compreendendo que todas as pessoas são semelhantes nos aspectos físicos, mentais e espirituais ${ }^{16}$.
Destaca-se como de grande relevância que o trabalho multidisciplinar favorece a prestação de cuidados humanizados, pois a interação de conhecimentos das mais diversas áreas da saúde proporciona melhor planejamento terapêutico a quem procura assistência. E, para que ocorra uma junção eficaz e qualificada de saberes, é imprescindível ter comunicação efetiva. Condizente a isso, um trabalho científico menciona que, por meio da interlocução eficiente, é possível acontecer debates e aprimoramento de ideias, discussão de opiniões e troca de informações, almejando a estruturação de um objetivo comum, que é a oferta do atendimento humanizado?.

Outros estudos afirmam que, para se prestar um atendimento de qualidade e que traga respostas satisfatórias às necessidades do paciente, é imprescindível a atuação coletiva aliada à comunicação objetiva e clara. Por meio de trabalho em equipe, organização e divisão de tarefas, elaboração de ações ordenadas e compartilhamento de opiniões e ideias, é possível proporcionar integralidade e continuidade da assistência ao paciente, abrangendo todo seu contexto biopsicossocial. Além do mais, lapsos na relação entre comunicação interdisciplinar e atuação em equipe podem suscitar complicações irreversíveis de saúde aos pacientes e, por consequência, minorar a eficiência dos cuidados prestados ${ }^{17,18}$.

Logo, a qualidade na prestação de cuidados humanizados no CC, entre outros fatores, depende da comunicação assertiva e do bom relacionamento interpessoal dos profissionais atuantes nesse setor. É nítida a importância da troca de saberes entre as equipes assistenciais, tendo em vista que todos são de grande relevância para que a prestação de cuidados aconteça da melhor forma possível, visando à qualidade e à eficiência ${ }^{16}$.

Conduzindo-se pela indagação sobre as dificuldades encontradas pelos profissionais na prestação da assistência humanizada no CC, foi de extrema relevância observar o que as equipes atuantes depreendem como dificuldades existentes no setor e que acometem a efetivação das práticas humanizadas. Todas as equipes, de maneira congruente, evidenciaram como dificuldades a conjuntura que denota o CC como um ambiente com alto fluxo de pacientes de demanda transitória, em paralelo à alta demanda de atribuições a serem realizadas e à pequena e desproporcional quantidade de funcionários.

Em consonância com os apontamentos citados, alguns autores consideram que a falta de tempo dos profissionais atuantes no CC é um entrave para a aplicabilidade de cuidados humanizados aos pacientes. Essa problemática pode 
ocorrer em consequência do excesso de procedimentos realizados, com curto intervalo entre eles, do baixo quadro de funcionários e da exorbitância de práticas burocráticas que toma da equipe, especialmente a de enfermagem, muito tempo do seu turno de trabalho, fazendo com que a afabilidade direta a cada paciente seja diminuída ou até mesmo inexistente ${ }^{19}$.

Além do mais, consolidando a relevância dos achados desta pesquisa acerca das dificuldades para humanizar, os mesmos autores do parágrafo anterior apontam que o número desproporcional de profissionais, em comparativo à abundância de pacientes, inviabiliza a aplicação da humanização, resultando na despersonalização das relações humanas entre a equipe multidisciplinar e o paciente cirúrgico, deteriorando a eficiência do cuidado oferecido ${ }^{19}$.

Em meio a uma análise minuciosa e comparativa das falas apresentadas pelas categorias profissionais, percebeu-se uma disparidade de concepções em relação ao encargo da equipe multidisciplinar, já que todas as equipes se designaram como a principal responsável pelo cumprimento das práticas humanizadas, desvinculando-se do atributo primordial ao correto desempenho das práticas multidisciplinares, que é o trabalho em equipe. Contudo todas as equipes manifestaram consenso ao referir que sua profissão pode contribuir promovendo orientação e conforto aos pacientes e seus acompanhantes, mantendo-os cientes de todos os processos inerentes ao procedimento em questão.

Em paralelo aos apontamentos supracitados, achados de uma pesquisa apontam que a orientação é vista como parte fundamental do processo de humanização para amparar o paciente e deixá-lo confortável e confiante em relação aos procedimentos que irão ocorrer e que é fragmento constituinte das atribuições de cada classe profissional. Para que isso ocorra, é fundamental estabelecer um processo claro de comunicação na relação profissional-paciente, visto que o estabelecimento de uma boa comunicação denota o sentimento que o paciente vai suscitar em meio à experiência vivenciada ${ }^{11}$.

Já ante a inquisição categórica sobre como deve ocorrer a responsabilização da equipe multidisciplinar acerca da assistência humanizada, a maioria dos profissionais demonstrou prolixidade na questão, fato esse que constituiu uma série de concepções repetitivas sobre ela, as quais alguns apontaram a responsabilização como uma tarefa coletiva e outros como uma tarefa individual, inerente a cada profissional. Contudo houve consonância interdisciplinar relacionada à autoimposição e à cobrança a respeito da implementação das práticas humanizadas que, segundo alguns profissionais, é uma tarefa a ser executada pelas chefias de equipe.

Com base no exposto, é nítido que há falha em um dos processos primordiais do fluxo do CC, que é o trabalho em equipe. Um estudo traz que a base do desenvolvimento interpessoal é a comunicação; por meio dela, é possível influenciar atitudes, tanto positivas quanto negativas, além de constituir competências de caráter multiprofissional. Assim, pelo estabelecimento de uma comunicação eficaz entre as equipes, será possível compor uma dinâmica de trabalho favorável à prestação de assistência humanizada e de qualidade ${ }^{20}$.

\section{CONCLUSÃO}

Para a equipe multidisciplinar, a assistência humanizada envolve aspectos inerentes à condição de ser humano, como proporcionar bem-estar ao próximo, ser empático ante suas angústias e acolhedor ante suas necessidades, compreendendo o indivíduo como único e insubstituível. Alguns entrevistados compreenderam que a humanização necessita de trabalho em equipe, aliado à comunicação efetiva. É imprescindível que haja consonância e cooperação mútua, tendo em vista que os cuidados humanitários devem partir de todos, não apenas de alguns.

Outros apontamentos relacionaram a sobrecarga de trabalho, a insuficiência de profissionais, a falta de tempo e o excesso de pacientes a complicadores que desfavorecem a assistência humanizada. É importante mencionar que condições adequadas nos ambientes laborais são de grande relevância para a qualidade dos atendimentos. Contudo seria realmente essencial adequar os apontamentos aludidos anteriormente para humanizar a assistência no CC? A humanização não deveria ser uma premissa intrínseca ao ser humano?

É evidente que as questões que envolvem a terminologia humanização são amplas e que, somente neste trabalho, se torna complexo detalhar e expor todos os campos que circundam essa abordagem. Logo, buscar um aprofundamento teórico-prático concernente ao expresso nesta pesquisa pode abrir margem para novos olhares, novos questionamentos e novas perspectivas. 


\section{REFERÊNCIAS}

1. Benevides R, Passos E. Humanização na saúde: um novo modismo? Interface (Botucatu). 2005;9(17):389-94. https://doi.org/10.1590/ S1414-32832005000200014

2. Souza LAP, Mendes VLF. 0 conceito de humanização na Política Nacional de Humanização (PNH). Interface (Botucatu). 2009;13(Supl. 1):681-8. https://doi.org/10.1590/S1414-32832009000500018

3. Waldow VR, Borges RF. Cuidar e humanizar: relações e significados. Acta Paul Enferm. 2011;24(3):414-8. https://doi.org/10.1590/ S0103-21002011000300017

4. Casate JC, Correa AK. Humanização do atendimento em saúde: conhecimento veiculado na literatura brasileira de enfermagem. Rev Latino-Am Enferm. 2005;13(1):105-11. https://doi.org/10.1590/ S0104-11692005000100017

5. Silva DC, Alvim NAT. Ambiente do centro cirúrgico e os elementos que o integram: implicações para os cuidados de enfermagem. Rev Bras Enferm. 2010;63(3):427-34. https://doi.org/10.1590/ S0034-71672010000300013

6. Carvalho PA, Göttems LBD, Pires MRGM, Oliveira MLC. Cultura de segurança no centro cirúrgico de um hospital público, na percepção dos profissionais de saúde. Rev Latino-Am Enferm. 2015;23(6):10418. https://doi.org/10.1590/0104-1169.0669.2647

7. Oliveira Júnior NJ, Moraes CS, Marques Neto S. Humanização no centro cirúrgico: a percepção do técnico de enfermagem. Rev SOBECC. 2012;17(3):43-9.

8. Stumm EMF, Macalai RT, Kirchner RM. Dificuldades enfrentadas por enfermeiros em um centro cirúrgico. Texto Contexto Enferm. 2006;15(3):464-71. https://doi.org/10.1590/ S0104-07072006000300011

9. Duarte MLC, Noro A. Humanização: uma leitura a partir da compreensão dos profissionais da enfermagem. Rev Gaúcha Enferm. 2010;31(4):685-92. https://doi.org/10.1590/ S1983-14472010000400011

10. Bedin E, Ribeiro LBM, Barreto RASS. Humanização da assistência de enfermagem em centro cirúrgico. Rev Eletron Enferm [Internet].
2004 [acessado em 21 ago. 2018];6(3):400-409. Disponível em: https://doi.org/10.5216/ree.v6i3.829

11. Medina RF, Backes VMS. A humanização no cuidado com o cliente cirúrgico. Rev Bras Enferm. 2002;55(5):522-7. https://doi. org/10.5935/0034-7167.20020068

12. Bardin L. Análise de conteúdo. Lisboa: Edições 70; 1977.

13. Câmara RH. Análise de conteúdo: da teoria à prática em pesquisas sociais aplicadas às organizações. Gerais Rev Interinst Psicol. 2013;6(2):179-91.

14. Silva FD, Chernicharo IM, Ferreira MA. Humanização e desumanização: a dialética expressa no discurso de docentes de enfermagem sobre o cuidado. Esc Anna Nery. 2011;15(2):306-13. https://doi. org/10.1590/S1414-81452011000200013

15. Faquinello P, Higarashi IH, Marcon SS. 0 atendimento humanizado em unidade pediátrica: percepção do acompanhante da criança hospitalizada. Texto Contexto Enferm. 2007;16(4):609-16. https:// doi.org/10.1590/S0104-07072007000400004

16. Costa CA, Lunardi FWD, Soares NV. Assistência humanizada ao cliente oncológico: reflexões junto à equipe. Rev Bras Enferm. 2003;56(3):3104. https://doi.org/10.1590/S0034-71672003000300019

17. Oliveira EM, Spiri WC. Programa Saúde da Família: a experiência de equipe multiprofissional. Rev Saúde Pública. 2006;40(4):72733. https://doi.org/10.1590/S0034-89102006000500025

18. Nogueira JWS, Rodrigues MCS. Comunicação efetiva no trabalho em equipe em saúde: um desafio para a segurança do paciente. Rev Cogitare Enferm. 2015;20(3):636-40. http://dx.doi.org/10.5380/ce.v20i3.40016

19. Mendonça ET, Lopes JM, Ribeiro L, Sá FBB, Oliveira DM, Salgado PO. Concepções de técnicos de enfermagem acerca da humanização da assistência em centro cirúrgico. RECOM [Internet]. 2016 [acessado em 18 abr. 2020];6(3):2389-97. Disponível em: https://doi.org/10.19175/ recom.v6i3.1177

20. Braga E, Berti H, Risso A, Silva M. Relações interpessoais da equipe de enfermagem em centro cirúrgico. Rev SOBECC. 2009;14(1):22-9. 